\title{
Enhanced priming of adaptive immunity by a proapoptotic mutant of Mycobacterium tuberculosis
}

\author{
Joseph Hinchey, ${ }^{1}$ Sunhee Lee, ${ }^{1,2}$ Bo Y. Jeon, ${ }^{3}$ Randall J. Basaraba, ${ }^{4}$ Manjunatha M. \\ Venkataswamy, ${ }^{1}$ Bing Chen, ${ }^{1,2}$ John Chan, ${ }^{1,5}$ Miriam Braunstein, ${ }^{6}$ lan M. Orme, ${ }^{4}$ Steven C. Derrick, ${ }^{3}$ \\ Sheldon L. Morris, ${ }^{3}$ William R. Jacobs Jr., ${ }^{1,2}$ and Steven A. Porcelli, ${ }^{1,5}$ \\ ${ }^{1}$ Department of Microbiology and Immunology and ${ }^{2}$ Howard Hughes Medical Institute, Albert Einstein College of Medicine, New York, New York, USA \\ ${ }^{3}$ Center for Biologics Evaluation and Research, US Food and Drug Administration, Bethesda, Maryland, USA. ${ }^{4}$ Department of Microbiology, \\ Immunology and Pathology, Colorado State University, Fort Collins, Colorado, USA. ${ }^{5}$ Department of Medicine, Albert Einstein College of Medicine, \\ New York, New York, USA. ${ }^{6}$ Department of Microbiology, University of North Carolina, Chapel Hill, North Carolina, USA.
}

\begin{abstract}
The inhibition of apoptosis of infected host cells is a well-known but poorly understood function of pathogenic mycobacteria. We show that inactivation of the secA2 gene in Mycobacterium tuberculosis, which encodes a component of a virulence-associated protein secretion system, enhanced the apoptosis of infected macrophages by diminishing secretion of mycobacterial superoxide dismutase. Deletion of $\sec A 2$ markedly increased priming of antigen-specific $\mathrm{CD8}^{+} \mathrm{T}$ cells in vivo, and vaccination of mice and guinea pigs with a secA2 mutant significantly increased resistance to $M$. tuberculosis challenge compared with standard $M$. bovis bacille CalmetteGuérin vaccination. Our results define a mechanism for a key immune evasion strategy of M. tuberculosis and provide what we believe to be a novel approach for improving mycobacterial vaccines.
\end{abstract}

\section{Introduction}

Mycobacterium tuberculosis infects more than one-third of the world's population and causes $2-3$ million deaths annually (1). The only currently approved vaccine for tuberculosis (TB) is bacille Calmette-Guérin (BCG), which is an attenuated strain of $M$. bovis. This vaccine has been widely administered in TB-endemic regions, with little apparent impact on the prevalence of adult pulmonary $\mathrm{TB}$, the most common form of disease caused by M. tuberculosis (2). Given the difficulties inherent in antibiotic treatment of TB (i.e., cost and long duration of continuous therapy), the increasing prevalence of active disease due to HIV coinfection, and the emergence of multidrug resistance, there is an urgent need for the development of new and more effective candidate vaccines (3).

Effective host control of $M$. tuberculosis is critically dependent on both innate and adaptive immune responses, and detailed studies in mouse models show that priming of both $\mathrm{CD}^{+}$and $\mathrm{CD}^{+} \mathrm{T}$ cells is important for long-term control of latent infection and for vaccine-induced protection (4). However, many lines of evidence indicate that M. tuberculosis has evolved mechanisms to evade host immunity, in some cases by inhibiting the priming and effector functions of these $\mathrm{T}$ cell subsets (5). One property of $M$. tuberculosis that has been linked to evasion of host immune responses is its ability to prevent the death by apoptosis that is typically triggered upon infection of phagocytic cells by vacuolar bacterial pathogens (6-8). Whereas macrophages infected by nonpathogenic species of mycobacteria are observed to rapidly undergo apoptosis, virulent mycobacteria such as M. tuberculosis and M. bovis (including BCG) do not efficiently trigger this response (9-12). In vitro studies indi-

Nonstandard abbreviations used: BCG, bacille Calmette-Guérin; BMM, BM-derived macrophage; CD62L, CD62 ligand; RT, room temperature; SodA, superoxide dismutase A; TB, tuberculosis.

Conflict of interest: The authors have declared that no conflict of interest exists. Citation for this article: J. Clin. Invest. 117:2279-2288 (2007). doi:10.1172/JCI31947. cate that the death of infected cells by apoptosis contributes to clearance of the bacteria through activation of as-yet-undefined bactericidal mechanisms $(10,11)$. In addition, apoptosis of infected cells has been shown to facilitate the transfer of mycobacterial antigens for presentation to T cells through MHC class I and CD1 molecules, which has been designated the "detour pathway" for antigen cross-presentation (13-15). Thus, the inhibition of the apoptotic response of infected host cells by $M$. tuberculosis is likely to interfere with both innate and adaptive immunity against this pathogen and most likely represents an important immune evasion strategy of this bacterium.

Although previous studies clearly document the antiapoptotic properties of M. tuberculosis, little is known regarding the mechanism of this immune evasion strategy, nor have any specific genes of $M$. tuberculosis controlling this aspect of virulence been reported. Here we show that the secA2 gene of M. tuberculosis, which encodes a component of a virulence-associated bacterial protein secretion system, is required for prevention of apoptosis of M. tuberculosis-infected macrophages. Our analyses showed that this was attributable to SecA2-dependent secretion of mycobacterial superoxide dismutase A (SodA). Infection with a secA2 deletion mutant of $M$. tuberculosis not only led to markedly increased levels of apoptosis by infected macrophages, but was also associated with significant enhancement in the priming of naive antigenspecific $\mathrm{CD}^{+} \mathrm{T}$ cells in vivo, suggesting increased engagement of the apoptosis-dependent detour pathway for MHC class Irestricted cross presentation. Vaccination of mice or guinea pigs with the secA2-deleted strain generated a level of protective host immunity against challenge with virulent $M$. tuberculosis that was significantly greater according to several criteria than the protection induced by BCG vaccination. These findings suggest a novel and practical approach to improving live TB vaccine strains by genetic modifications that disrupt their ability to interfere with host cell apoptosis. 


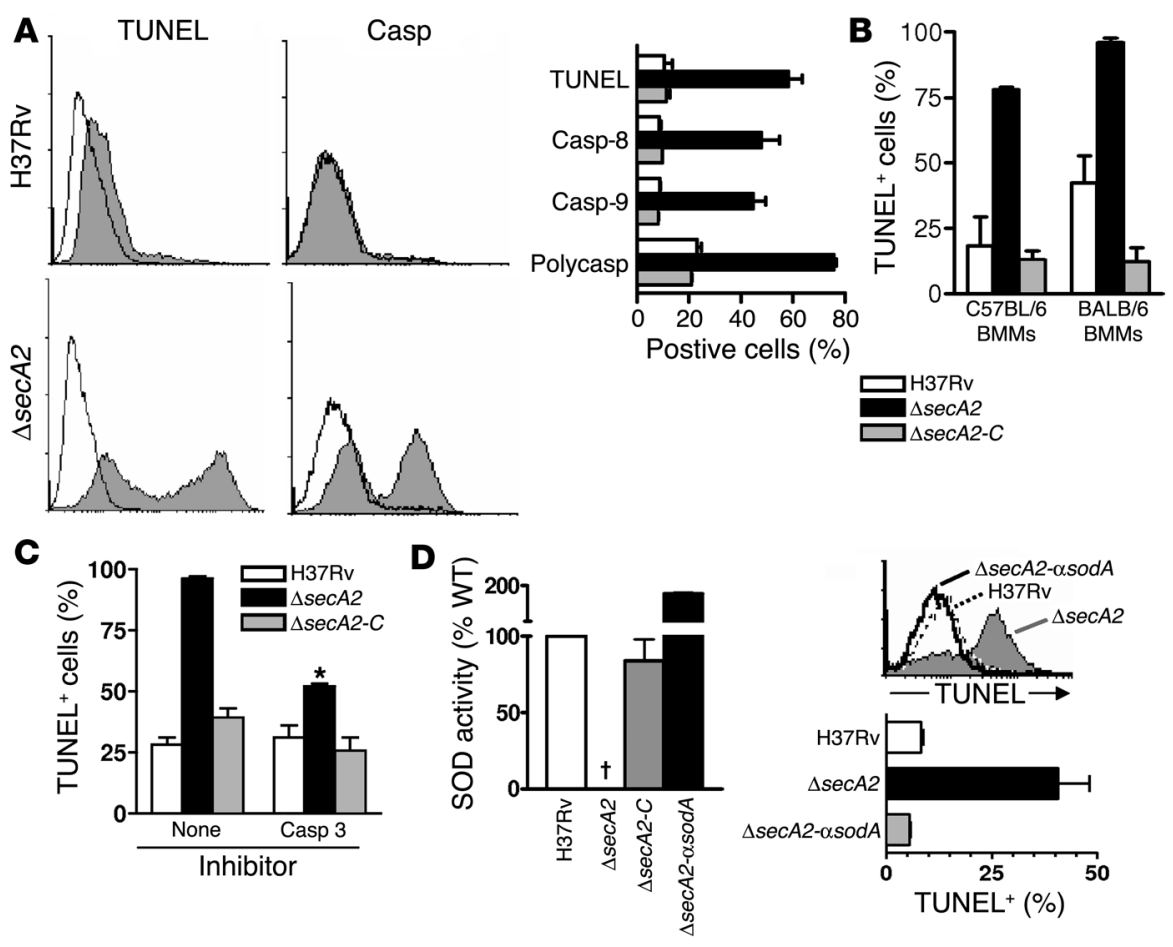

Figure 1

Induction of caspase and SodA-dependent apoptosis in macrophages by infection with $M$. tuberculosis $\Delta s e c A 2$. (A) Human THP-1 cells were infected with $M$. tuberculosis (H37Rv), $\Delta s e c A 2$, and complemented $\triangle \sec A 2(\triangle \sec A 2-C)$ strains at an $\mathrm{MOI}$ of 10 . Cells were stained after 48 and 72 hours for TUNEL or for caspase activation using FLICA probes and analyzed by FACS. Representative histograms of staining with TUNEL or a polycaspase-specific probe (fluoresceinVAD-FMK) at 48 hours are shown (open histogram, uninfected; filled histogram, infected with H37Rv or $\triangle$ secA2 as indicated). Quantitation by FACS of cells positive for TUNEL or for active caspase-8, caspase-9, or polycaspase is summarized. Data shown are from the time points for peak signal detection (48 hours for TUNEL and polycaspase, 72 hours for caspase-8 and 9). (B) TUNEL staining of mouse BMMs 72 hours after infection with indicated bacterial strains. Staining was quantitated by FACS as in A. (C) TUNEL staining of THP-1 cells infected with the indicated bacteria for 48 hours in the absence or presence of caspase-3-specific inhibitor (Z-DEVD-FMK). ${ }^{*} P<0.001$ compared to no inhibitor (1-way ANOVA, Bonferroni post-test). (D) Filtrates from cultures of H37Rv, $\triangle \sec A 2$ mutant, or $\triangle \sec A 2-\alpha s o d A$ were analyzed for SodA activity (left). Graph shows mean and range for duplicate samples, with SodA activity normalized to the level of WT $(\mathrm{H} 37 \mathrm{Rv})$. ${ }^{\dagger}$ Below detection level. The $\triangle$ secA2- $\alpha$ sodA showed restoration of SodA activity in the culture filtrate and also reversed the TUNEL ${ }^{+}$cell death induced by $\triangle$ secA2 in THP-1 cells infected for 48 hours at an MOI of 10:1 (right).

\section{Results}

Essential role of the secA2 gene of $M$. tuberculosis in preventing apoptosis of infected macrophages. The secA2 gene (Rv1821) encodes an accessory secretion factor in $M$. tuberculosis that is required for the export of a small subset of proteins that includes SodA, an M. tuberculosis enzyme that catalyzes conversion of superoxide anions to hydrogen peroxide (16). Whereas deletion of secA2 from M. tuberculosis has no effect on growth in culture, it does result in partial growth attenuation in vivo. This may be explained in part by the loss of SodA secretion, which would be expected to result in a reduced ability of the intracellular bacteria to detoxify superoxide anions generated in host cells in response to infection (17). However, overproduction of superoxide anions is also linked to induction of apoptosis in a variety of experimental systems (18), which suggested that another important function of secreted mycobacterial SodA may be to inhibit the infection-induced apoptosis of host cells. Indeed, when compared with nonpathogenic species of mycobacteria that are known to be proapoptotic, pathogenic mycobacteria such as $M$. tuberculosis express markedly higher levels of SodA (19), and antisense inhibition of SodA expression in M. tuberculosis results in reduced bacterial growth and higher levels of apoptosis in tissues of infected mice (20).

To directly examine a role for $\sec A 2$ in the inhibition of apoptosis, transformed human monocyte/macrophage cells (THP-1 cells) or primary mouse BMderived macrophages (BMMs) (C57BL/6 or BALB/c strains) were infected at an MOI of 10 bacilli per macrophage with WT M. tuberculosis (strain $\mathrm{H} 37 \mathrm{Rv}$ ), a mutant of $\mathrm{H} 37 \mathrm{Rv}$ with a $\sec A 2$ deletion $(\triangle \sec A 2)$, or a complemented strain of the mutant $(\Delta \sec A 2-\mathrm{C})$. After 72 hours, quantitative assessment of apoptosis by staining for DNA strand breakage (TUNEL) and polycaspase activation showed that $\triangle \sec A 2$ strongly induced both of these markers of apoptosis in both human and murine macrophages, whereas WT M. tuberculosis did not (Figure 1, A and B, and Supplemental Figure 1; supplemental material available online with this article; doi:10.1172/ JCI31947DS1). The enhanced TUNEL staining was fully reversed with $\triangle \sec A 2-\mathrm{C}$, which behaved identically to the WT strain (Figure 1, A and B).

Caspases are known to be activated by infection with virulent as well as nonvirulent strains of $M$. tuberculosis (10, 21), although under certain conditions, induction of macrophage death by M. tuberculosis has been reported to proceed in a caspase-independent manner (22). The involvement of caspases in apoptosis induced by $\Delta \sec A 2 \mathrm{M}$. tuberculosis was evaluated by measuring total caspase activity and activities of caspases 8 and 9 at 48 and 72 hours after infection in THP- 1 cells (Figure 1A, and data not shown). Caspases 8 and 9 were selected because they are known to be initiators of the extrinsic (receptor-mediated) and intrinsic (mitochondrial) cell death pathways, respectively (23). The 2 caspases were equally activated in cells infected with $\Delta \sec A 2$ but not in cells infected with either WT M. tuberculosis or the complemented $\Delta s e c A 2-C$. This suggested the involvement of both extrinsic and intrinsic caspase-dependent pathways for initiation of apoptosis by $\Delta \sec A 2$. Furthermore, treatment of THP-1 cells with an irreversible specific inhibitor of caspase-3 prior to infection with the $\triangle \sec A 2$ mutant strongly reduced TUNEL staining, indicating that the macrophage cell death induced by $\Delta s e c A 2$ was dependent on the activation of this downstream caspase (Figure 1C).

Reversal of proapoptotic phenotype of $M$. tuberculosis $\Delta$ sec $A 2$ by restoration of SodA secretion. In contrast to mycobacterial proteins that 

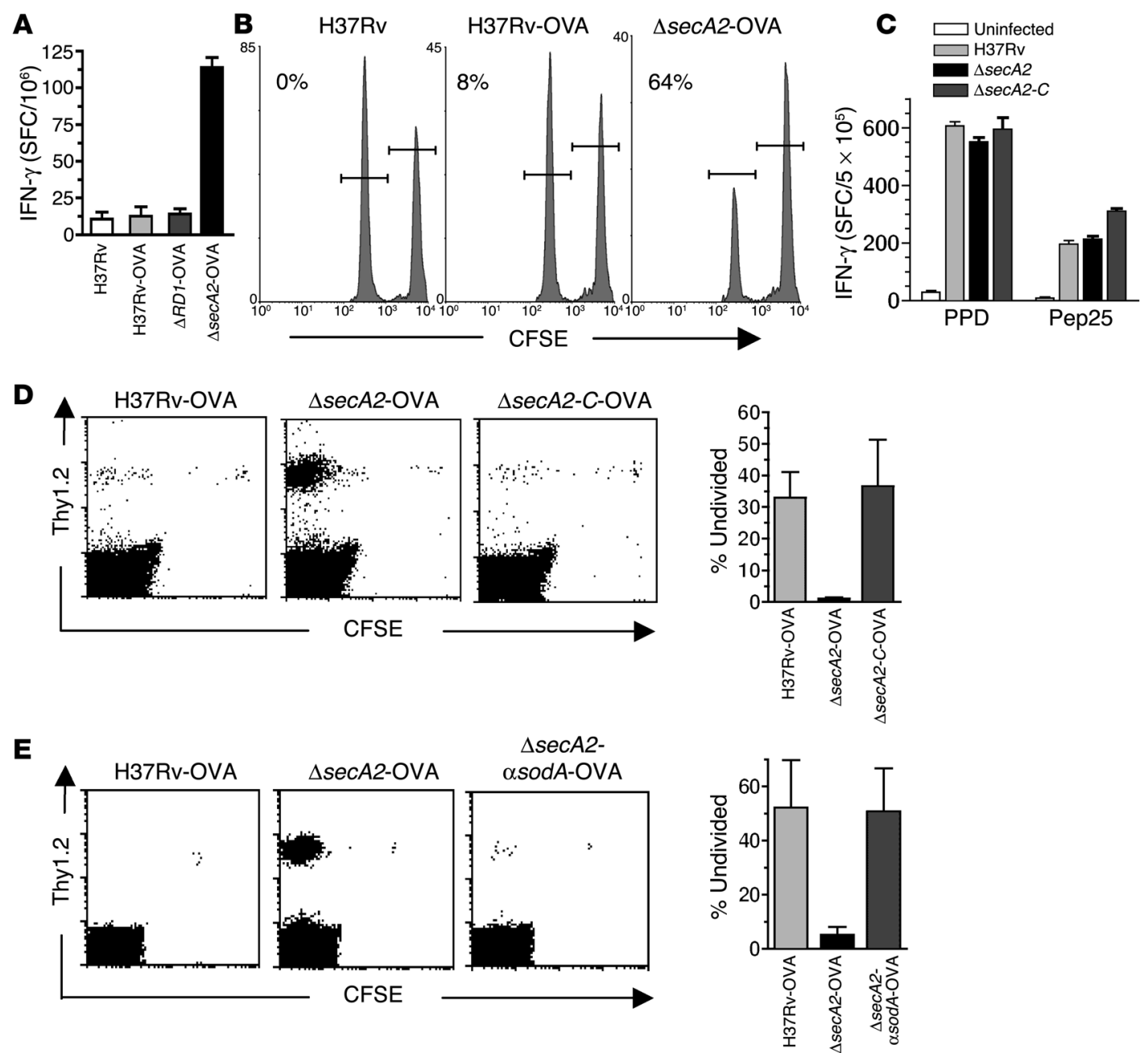

Figure 2

Enhanced CD8 ${ }^{+} \mathrm{T}$ cell activation in vivo by $\Delta \sec A 2$. (A) Mice were infected i.v. with the indicated bacterial strains, and spleens were harvested after 7 days for quantitation of SIINFEKL-specific T cells by IFN- $\gamma$ ELISPOT. SFC, spot-forming cells. (B) CTL activity was measured in vivo by transfer of a mixture of SIINFEKL-pulsed CFSElow and unpulsed CFSEhigh splenocytes into recipient mice 14 days after infection with the indicated bacteria. Relative proportions of CFSElow and CFSEhigh were quantitated by FACS to determine percent specific lysis. (C) CD4 ${ }^{+} \mathrm{T}$ cell responses were unaffected by deletion of $\sec A 2$. Seven days after infection with indicated bacteria, responses of splenocytes to purified protein derivative (PPD) and peptide-25 (Pep25) were determined by ELISPOT. (D) Thy1.1+ B6.PL mice were injected with CFSE-labeled Thy1.2+ OT-I splenocytes, and infected with the indicated bacteria. CD8 ${ }^{+}$T cell activation was assessed 6 days after infection by CFSE dilution. Dot plots show representative mice, and bar graphs show means and SDs for percentages of undivided cells in the transferred population for 2 or 3 mice per bacterial strain. (E) The enhanced CD8+ T cell proliferation induced by $\triangle$ secA2 was reversed by reexpression of SodA secretion in the $\triangle \sec A 2-\alpha s o d A$ strain. Dot plots show CFSE dilution in the transferred population 6 days after infection with the indicated strains. The bar graph on the right shows means and SDs of the percentages of undivided cells for groups of 4 mice infected with each bacterial strain. All results are representative of at least 2 independent experiments.

undergo signal peptide-dependent secretion by the secA1-dependent pathway, SodA does not possess a recognizable $\mathrm{N}$-terminal signal sequence. We therefore reasoned that extending the $\mathrm{N}$ terminus of SodA with a signal sequence from a mycobacterial protein secreted by a secA2-independent pathway might restore SodA secretion in the $\triangle \sec A 2$ mutant and reverse its apoptosisinducing phenotype. This was tested by extending the $5^{\prime}$ end of the coding sequence for WT SodA with a sequence encoding the $\mathrm{N}$-terminal signal sequence of Ag85b, a major M. tuberculosis protein that is secreted in a secA1-dependent and secA2-independent manner (16). Expression of this construct in the $\triangle \sec A 2$ mutant $(\triangle \sec A 2-\alpha \operatorname{sod} A)$ restored SodA activity in the culture filtrate and also reversed the induction of apoptosis in infected THP-1 cells (Figure 1D). This result indicated that secretion of SodA was likely to be the major secA2-dependent process involved in the inhibition of host cell apoptosis.

Deletion of secA2 enhanced $C D 8^{+} T$ cell priming in vivo. Studies of Salmonella typhimurium and other vacuolar bacteria show that death of infected cells by apoptosis leads to efficient uptake of bacterial antigens by host DCs and cross-presentation to MHC class Irestricted $\mathrm{CD}^{+} \mathrm{T}$ cells (8). Because $M$. tuberculosis antigens are generated within a phagosomal compartment that is sequestered from the classical cytoplasmic pathway of antigen processing, display of these antigens on MHC class I molecules is likely to 
A
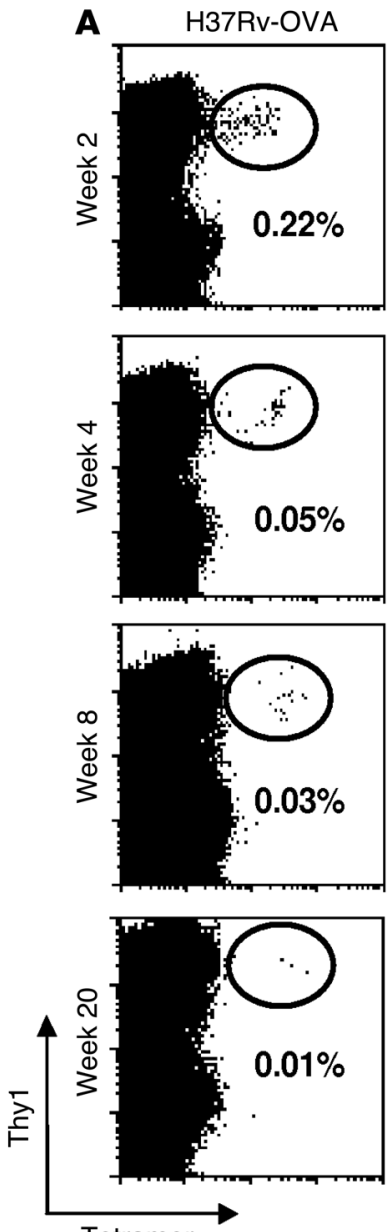

Tetramer $\triangle \sec A 2-O V A$
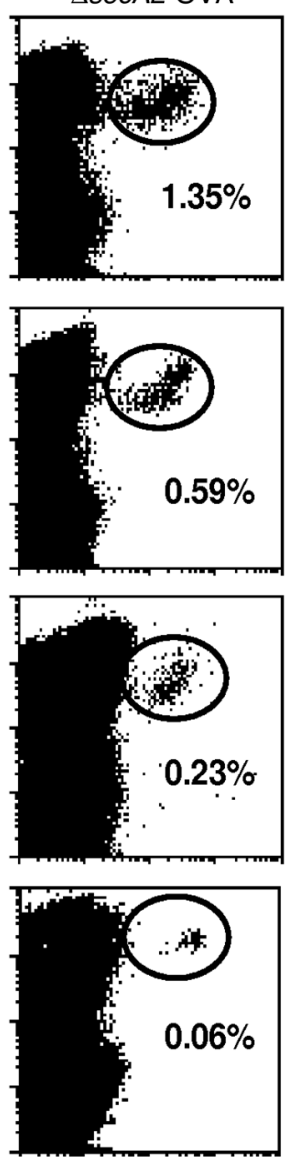

B
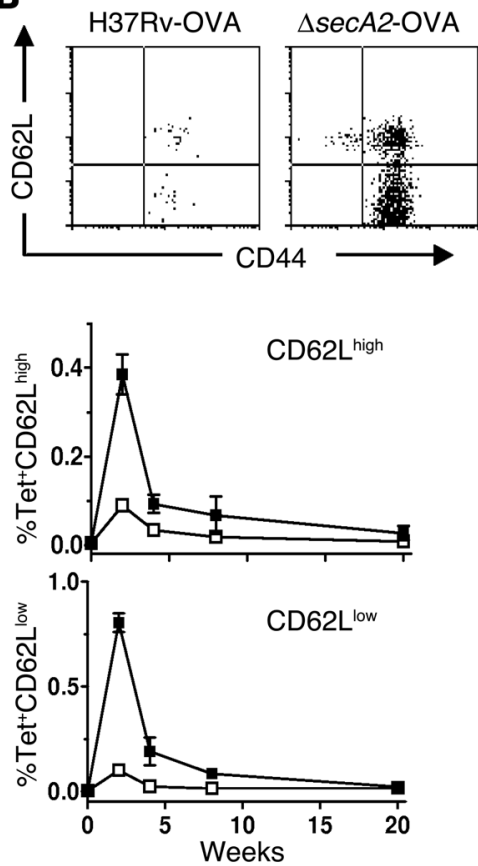

Figure 3

Augmented memory $\mathrm{T}$ cell populations following immunization with $\Delta s e c A 2$. C57BL/6 mice were adoptively transferred with $5 \times 10^{5}$ OT-I splenocytes 24 hours prior to vaccination by subcutaneous infection with either H37Rv-OVA or $\triangle$ secA2-OVA. The animals were sacrificed 2, 4, 8, and 20 weeks after vaccination, and splenocytes were stained for 5-color fluorescence analysis using antibodies specific to Thy1.2, B220, CD62L, and CD44 plus SIINFEKL-loaded $\mathrm{H}-2 \mathrm{~K}^{\mathrm{b}}$ tetramer. (A) FACS analysis of total B220- events among $1.5 \times 10^{6}$ total lymphocytes, showing proportions of Thy $1.2^{+}$cells staining with tetramer. (B) Dot plots show expression of CD44 and CD62L on cells gated for tetramer staining as in $\mathbf{A}$ from representative mice sacrificed 2 weeks after infection with the indicated bacterial strains. The graphs show percentages of total B220- lymphocytes staining with tetramer (Tet) and expressing either high or low levels of CD62L at each time point after vaccination. Filled squares represent $\Delta$ secA2-vaccinated mice and open squares, H37Rv-OVA-vaccinated mice. Each symbol represents mean and SD for groups of 2 or 3 mice. depend on an indirect route of presentation through bystander DCs, which can take up and process material released from apoptotic infected macrophages via the previously described detour pathway for cross-presentation (13-15). Based on our observation of enhanced apoptosis by the $\Delta \sec A 2$ mutant in vitro, we predicted that this mutant should also facilitate transmission of antigens to bystander DCs and enhance $\mathrm{CD}^{+} \mathrm{T}$ cell priming. To test this in vivo, we expressed a plasmid encoding the $M$. tuberculosis 19-kDa lipoprotein fused at its $\mathrm{C}$ terminus to the $\mathrm{H}-2 \mathrm{~K}^{\mathrm{b}}-$ binding sequence of OVA (SIINFEKL) in WT M. tuberculosis (H37Rv-OVA), an attenuated mutant of $M$. tuberculosis with a deletion of the RD1 region (24) ( $\triangle R D 1$-OVA), or the $\triangle \sec A 2$ mutant ( $\triangle \sec A 2$-OVA) (Supplemental Figure 2). Mice were infected with clones of these recombinant mycobacteria expressing comparable levels of the 19-kDa lipoprotein-SIINFEKL fusion protein (Supplemental Figure $2 \mathrm{~A}$ ), and SIINFEKL-responsive $\mathrm{CD}^{+} \mathrm{T}$ cells in their spleens were enumerated by IFN- $\gamma$ ELISPOT. Whereas infection with H37Rv, H37Rv-OVA, or $\triangle R D 1$-OVA induced only background levels of IFN- $\gamma$ spot-forming cells, the $\triangle \sec A 2-O V A$ infection induced a significant, 10-fold increase above background levels (Figure 2A). As another important gauge of $\mathrm{CD}^{+} \mathrm{T}$ cell priming, we assessed SIINFEKL-specific cytolytic activity using an in vivo CTL assay. This revealed weak cytolytic activity in mice infected with $\mathrm{H} 37 \mathrm{Rv}$ OVA but a substantial increase in target-specific killing in mice infected with $\triangle \sec A 2-O V A$ (Figure $2 \mathrm{~B}$ ). In contrast to the clear enhancement of $\mathrm{T}$ cell responses against an MHC class I-presented epitope in animals primed with the $\Delta s e c A 2-O V A$ strain, IFN- $\gamma$ ELISPOT responses to crude exogenous mycobacterial proteins contained in M. tuberculosis purified protein derivative (PPD) or the dominant MHC class II-presented epitope of Ag85B (Pep25) were similar in animals infected with WT and $\triangle \sec A 2 \mathrm{M}$. tuberculosis (Figure 2C). This indicated that enhancement of T cell priming by the $\Delta \sec A 2$ mutant was limited mainly or exclusively to the CD8 ${ }^{+}$ $\mathrm{T}$ cell compartment.

To directly visualize the priming of $\mathrm{MHC}$ class I-restricted CD8 ${ }^{+}$ $T$ cells reactive with SIINFEKL in the context of infection, we used adoptive transfer of CFSE-labeled naive T cells from SIINFEKL/ $\mathrm{H}-2 \mathrm{~K}^{\mathrm{b}}$-reactive TCR-transgenic OT-I mice (25). Thy $1.1^{+}$B6.PL mice were injected with CFSE-labeled Thy $1.2^{+}$splenocytes from OT-I mice, followed by infection with mycobacteria expressing the $19-\mathrm{kDa}$ lipoprotein-SIINFEKL fusion protein. $\mathrm{CD}^{+} \mathrm{T}$ cell activation and proliferation were assessed by dilution of CFSE in the transferred population at 5-7 days after infection (Figure 2D). Negligible proliferation of transferred OT-I T cells was observed in mice infected with $\mathrm{H} 37 \mathrm{Rv}$, and very modest proliferation was seen with $\mathrm{H} 37 \mathrm{Rv}$ OVA infection. In contrast, $\triangle \sec A 2$-OVA infection induced a massive increase in proliferation of transferred $\mathrm{T}$ cells, with the vast majority of cells undergoing 8 or more divisions. The response to $\Delta s e c A 2-$ OVA was most marked in mice that had been adoptively transferred with relatively small numbers $\left(3 \times 10^{5}\right)$ of OT-I T cells, consistent 
A
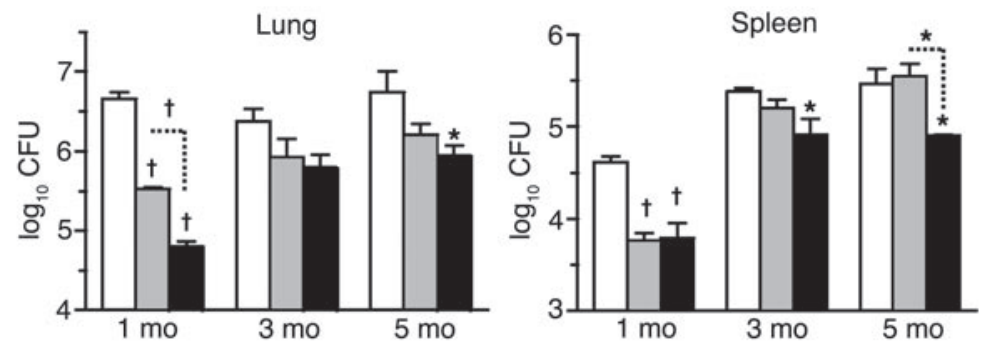

B
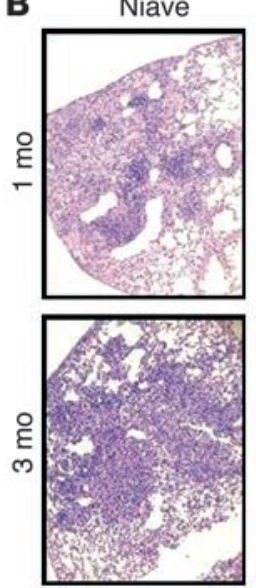

BCG
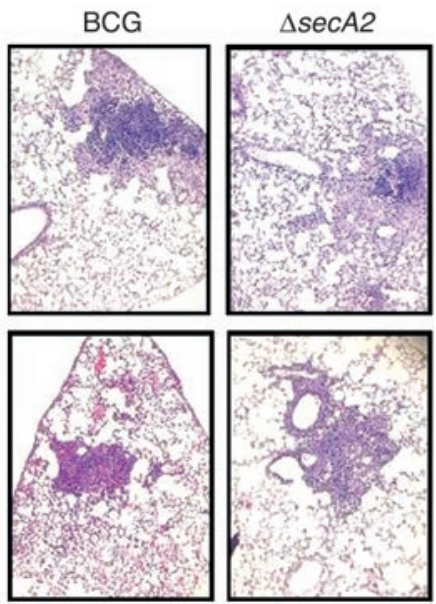

C

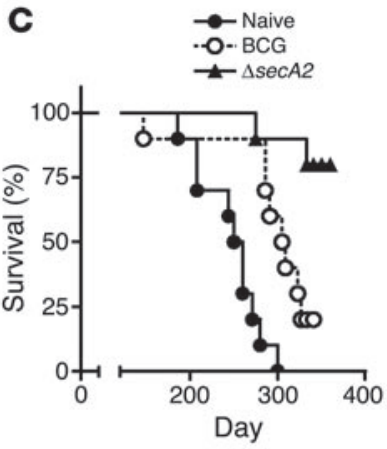

Figure 4

Protective immunity against virulent $M$. tuberculosis challenge in mice following vaccination with $\Delta$ secA2. (A) C57BL/6 mice were vaccinated subcutaneously with saline (naive) or with $1 \times 10^{6} B C G$ or $\triangle \sec A 2$ and challenged by aerosol 2 months later with $50-100$ CFU of virulent $M$. tuberculosis Beijing/W strain (HN878). Graphs show means and SDs of CFU of $M$. tuberculosis in lung and spleen at 1,3, and 5 months after challenge for groups of 5 mice that were either naive (white bars), BCG vaccinated (gray bars), or $\triangle$ secA2 vaccinated (black bars). ${ }^{*} P<0.05$ and ${ }^{t} P<0.001$, compared with unvaccinated group or between bracketed groups; 1-way ANOVA with Tukey's post-hoc test. (B) Lungs of mice vaccinated and challenged with virulent $M$. tuberculosis as in A were examined histologically at 1 and 3 months after challenge. More severe, spreading lung lesions with extensive granulomatous pneumonia and consolidation were observed in unvaccinated mice as compared with mice vaccinated with either BCG or $\triangle s e c A 2$. Original magnification, $\times 20$. (C) C57BL/6 mice were vaccinated subcutaneously with saline or with $1 \times 10^{6} \mathrm{BCG}$ or $\triangle$ secA2 and challenged by aerosol 2 months later with 50-100 CFU of virulent $M$. tuberculosis Erdman strain. Mice were observed daily for survival for 1 year after challenge. Moderate extension of survival was observed in BCG-vaccinated animals ( $P=0.006$ compared with naive control group; log rank test), and much more pronounced extension of survival was observed in $\Delta s e c A 2$-vaccinated animals $(P=0.0001$ compared with naive; $P=0.0062$ compared with $B C G)$.

with previous observations on the effect of precursor frequency on limiting $\mathrm{CD}^{+} \mathrm{T}$ cell expansion (26). Restoration of secA2 by complementation ( $\triangle \sec A 2$-C-OVA) reversed the effect of $\sec A 2$ deletion on OT-I T cell priming (Figure 2D). In contrast to the marked differences in OT-I T cell proliferation to infection by secA2-negative versus -positive strains, $\mathrm{CD} 8^{+} \mathrm{T}$ cell responses to lysates of the same strains injected subcutaneously with an adjuvant known to stimulate cross-priming (QS-21) were similar (Supplemental Figure 2C). This confirmed that the SIINFEKL epitope was produced in comparable amounts and in a potentially immunogenic form by all of the different recombinant mycobacterial clones, although efficient presentation of antigen originating from live mycobacteria to OT-I $T$ cells occurred only during infection by $\triangle \sec A 2$ bacilli.

Since selective reconstitution of secreted SodA activity by expression of $\alpha$ sodA completely reversed apoptosis induction by $\triangle \sec A 2$ mutants (Figure 1E), we assessed the effect of this on the priming and expansion of OT-I $\mathrm{T}$ cells by generating a $\triangle \sec A 2-\alpha \operatorname{sod} A$ strain expressing the 19-kDa lipoprotein-SIINFEKL fusion protein ( $\triangle \sec A 2$ - $\alpha$ sodA-OVA). Infection with $\triangle \sec A 2$-asodA-OVA resulted in markedly reduced expansion of adoptively transferred OT-I T cells compared with $\triangle$ secA2-OVA and was similar in this regard to WT H37RvOVA infection (Figure 2E). This indicated a tight linkage among enhanced $\mathrm{CD}^{+} \mathrm{T}$ cell priming, the loss of SodA secretion, and the inability of the bacterium to block apoptosis of its infected host cell.

Augmented memory $T$ cell populations following immunization with $\triangle \sec A 2$. An important benchmark for measuring the efficacy of a vaccine strain is the effect it has on the generation of long-lived memory $T$ cells. Because FACS analysis of endogenous OVA-specific $\mathrm{T}$ cells using SIINFEKL-loaded $\mathrm{H}-2 \mathrm{~K}^{\mathrm{b}}$ tetramers was not sufficiently sensitive for accurate quantitation (data not shown), we used adoptive transfer of low numbers $\left(5 \times 10^{5}\right)$ of OT-I T cells to boost the precursor frequency of OVA-specific $T$ cells. This enabled accurate quantitation of antigen-specific $\mathrm{CD}^{+}$ $\mathrm{T}$ cells by tetramer staining in mice vaccinated by subcutaneous injection with H37RvOVA or $\triangle$ secA2-OVA. By following levels of SIINFEKL-loaded $\mathrm{H}-2 \mathrm{~K}^{\mathrm{b}}$ tetramer ${ }^{+}$splenocytes over a period of 20 weeks, we observed that $\triangle \sec A 2$-OVA vaccinated mice showed an enhanced expansion phase of antigenspecific $\mathrm{CD}^{+} \mathrm{T}$ cells that was followed by a sustained maintenance phase characterized by increased levels of $\mathrm{CD}^{+}$memory $\mathrm{T}$ cells (Figure 3 ). We also measured expression of CD62 ligand (CD62L) and CD44 on the tetramer ${ }^{+}$cells to distinguish among naive $\left(\mathrm{CD} 44^{\text {low }} \mathrm{CD} 62 \mathrm{~L}^{\text {high }}\right)$, central memory $\left(\mathrm{CD} 44^{\text {high }} \mathrm{CD} 62 \mathrm{~L}^{\text {high }}\right)$, and effector memory (CD44 high $C D 62 L^{\text {low }}$ ) subsets (27). An increase in the long-term expansion of $\mathrm{CD}^{+}$memory $\mathrm{T}$ cells to at least 8 weeks after vaccination with $\triangle \sec A 2$ was apparent in both the $C D 62 \mathrm{~L}^{\text {high }}$ and $C D 62 \mathrm{~L}^{\text {low }}$ subsets, with a trend favoring greater and more persistent expansion in the $\mathrm{CD} 62 \mathrm{~L}^{\text {high }}$ population. We also observed higher expression of IL-7 receptor $\alpha$ chain and lower expression of the programmed death-1 receptor (PD-1) in expanded antigen-specific $\mathrm{CD}^{+} \mathrm{T}$ cells in $\triangle \sec A 2$-vaccinated mice at 20 weeks (data not shown), consistent with the generation of a long-lived and functionally intact population of memory $\mathrm{T}$ cells $(28,29)$.

Protective immunity against virulent $M$. tuberculosis challenge following vaccination with $\triangle \sec A 2$. In order to determine whether the enhanced T cell priming observed with $\triangle \sec A 2$ could increase its efficacy as a live vaccine strain, we conducted immunization and challenge studies designed to evaluate potential vaccine efficacy. C57BL/ 6 mice that were either naive or immunized 8 weeks earlier by subcutaneous inoculation with live $\Delta s e c A 2$ or BCG (Pasteur 

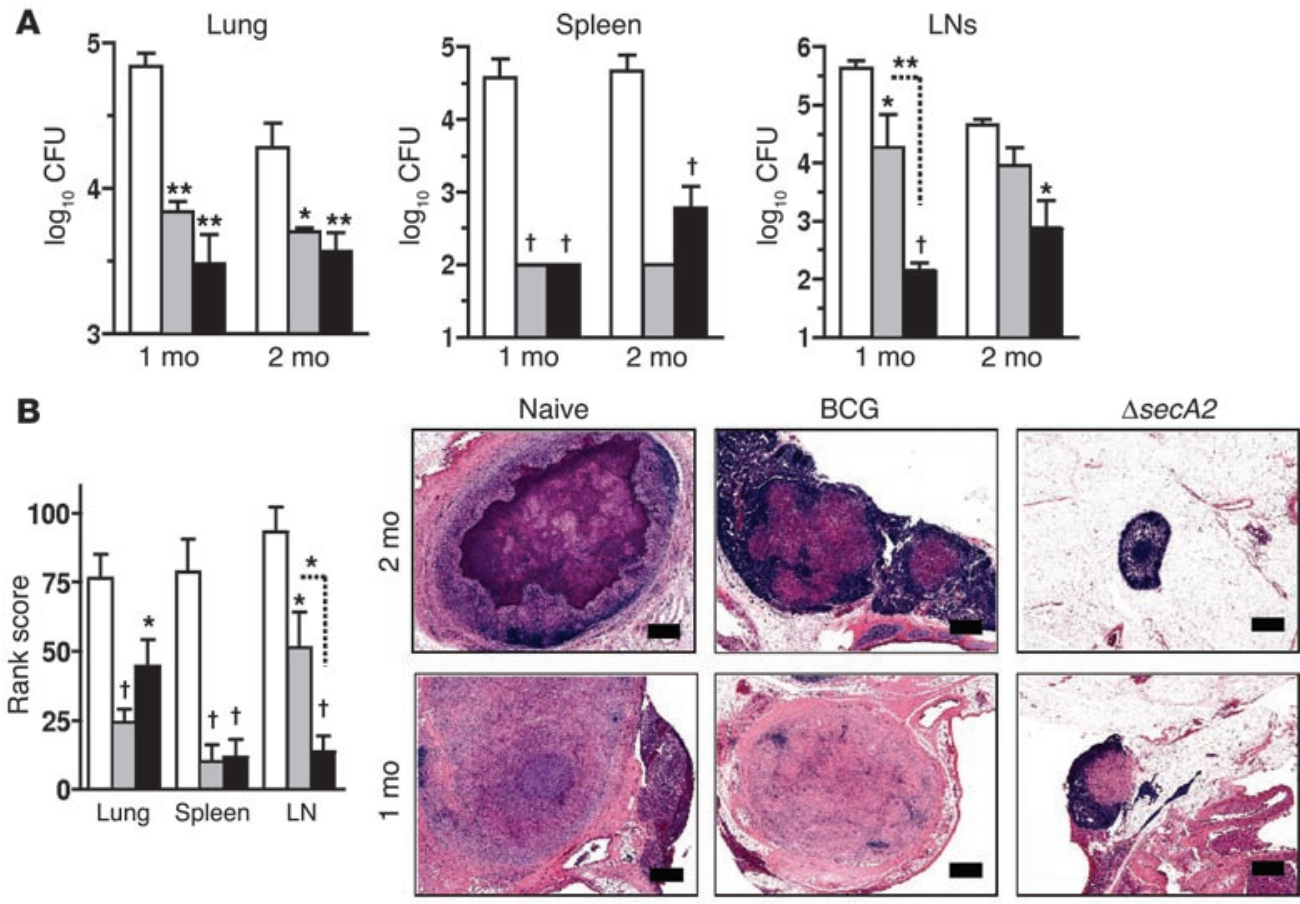

Figure 5

Protective immunity against virulent $M$. tuberculosis challenge in guinea pigs following vaccination with $\Delta s e c A 2$. (A) Outbred Hartley guinea pigs were vaccinated intradermally with saline, BCG, or $\triangle \sec A 2(n=5$ animals per group) and challenged by aerosol 2 months later with $10-30$ CFU of virulent $M$. tuberculosis H37Rv. Graphs show SEM of CFU of $M$. tuberculosis in lung, spleen, and mediastinal lymph nodes at 1 and 2 months after challenge for naive (white bars), BCG-vaccinated (gray bars), or $\Delta$ secA2-vaccinated (black bars) animals (CFU counts obtained from a minimum of 3 and in most instances 5 animals; an exception was 2-month spleen CFU for BCG-vaccinated animals, in which counts were obtained from only 1 animal for technical reasons). (B) Quantitative scoring of histopathology graphed as the SEM of the rank scores for the groups of guinea pigs vaccinated and challenged as described in A. Images show representative low-power ( $\times 25)$ views of H\&E-stained sections of mediastinal lymph nodes harvested from each group at 1 or 2 months after challenge. Scale bars: $1 \mathrm{~mm}$. ${ }^{*} P<0.05,{ }^{*} P<0.01$, ${ }^{\dagger} P<0.001$ compared with unvaccinated group or between bracketed groups; 1-way ANOVA with Tukey's post-hoc test.

strain) were challenged by low-dose aerosol infection with virulent $M$. tuberculosis (strain Beijing W/HN878). In naive mice, substantial growth in the lungs and dissemination to spleens were detected within 1 month of challenge. In contrast, vaccination with $\Delta s e c A 2$ and BCG considerably reduced M. tuberculosis bacillary loads in both lungs and spleens of aerosol-challenged mice as compared with naive controls at 1 month after aerosol challenge (Figure $4 \mathrm{~A})$. The protection evoked by $\Delta \sec A 2$ immunization was significantly greater than that obtained with BCG vaccination, as measured by bacterial burden in lung (0.72-log reduction in $\triangle \sec A 2$ versus $B C G$ vaccinated mice; $P<0.001)$. Immunization with $\Delta \sec A 2$ also showed a more prolonged effect on control of $M$. tuberculosis infection compared with BCG immunization, with reductions in CFU still apparent 5 months after challenge, when BCG immunization no longer showed significant effects. Moreover, the survival of M. tuberculosis-challenged mice vaccinated with $\Delta \sec A 2$ was significantly prolonged when compared with that of naive mice or mice vaccinated with BCG (Figure 4C). Histopathological examination of the lungs from mice immunized with either BCG or the $\Delta \sec A 2$ strain showed relatively mild inflammation with small and compact lymphocyte-rich granulomas, compared with naive mice, which had extensive, poorly organized granulomatous lesions (Figure 4B).

We also tested the protective capacity of $\Delta \sec A 2$ vaccination using an aerosol challenge model in guinea pigs, a host species highly susceptible to M. tuberculosis. Animals that were either naive or immunized 2 months previously with $\triangle \sec A 2$ or BCG were challenged by low-dose aerosol inoculation of M. tuberculosis H37Rv. At 1 and 2 months after challenge, guinea pigs immunized with M. tuberculosis $\triangle \sec A 2$ showed marked reductions in CFU in the spleens, lungs, and mediastinal lymph nodes relative to naive controls. Although BCG-immunized animals also showed similar reductions in CFU in the lung and spleen, these animals showed much less reduction of bacillary load in the mediastinal lymph nodes than was seen for the $\Delta s e c A 2$-immunized group (Figure $5 \mathrm{~A}$ ). The results of pathologic evaluation of guinea pig tissues paralleled the bacterial counts in the tissues (Figure 5B; Supplemental Figure 4). Again, the differences in the mediastinal lymph nodes were striking, as these were markedly enlarged in the naive and BCG-immunized groups but appeared normal in size and gross appearance in $\Delta \sec A 2$-immunized animals. Microscopically, the lymph nodes of both naive and BCG-immunized animals showed marked granulomatous reaction progressing to fibrosis that completely effaced the normal architecture of the nodes by 2 months, while the lymph nodes of $\Delta s e c A 2$-immunized animals appeared normal at 1 month and showed only small areas of fibrosis at 2 months after challenge. Taken together, these results in 2 different animal models of $M$. tuberculosis vaccination and challenge indicated that $\triangle \sec A 2$ was at least equal to BCG in all outcomes examined and significantly exceeded BCG in some measures of efficacy such 
as prolongation of survival and the ability to restrict extension of pulmonary infection into the regional lymphatic system.

\section{Discussion}

Our results confirm a significant role for inhibition of infected host cell apoptosis in the immune evasion strategy of M. tuberculosis and suggest the $\sec A 2$-dependent secretion of mycobacterial SodA as a key mechanism involved in this virulence-associated trait. In this regard, virulent mycobacteria appear to have adopted an evasion strategy that is characteristic of many viruses that also produce factors that can delay apoptotic host cell death (30). Whereas the ability of virulent mycobacteria to perform this function has been previously described $(9-11,22)$, the work reported here is to our knowledge the first demonstration of a specific genetic deletion in M. tuberculosis that curtails the ability of this organism to inhibit apoptosis of infected macrophages. Although our results showed that $\sec A 2$ was essential for the antiapoptotic properties of M. tuberculosis, it is likely that other mechanisms also cooperate with the secA2-dependent mechanism described here in blocking all of the multiple pathways that can initiate apoptosis. Indeed, our preliminary studies have identified at least 3 additional genes in M. tuberculosis that are required for effective blockade of infected macrophage apoptosis (unpublished observations), although it is currently unclear which pathways for induction or execution of programmed cell death these are inhibiting.

Several advantages may accrue to mycobacteria as a result of delaying or inhibiting macrophage apoptosis, including preservation of a protected growth environment and prevention of engagement of intrinsic microbicidal activities in the host cell $(31,32)$. The studies presented here also underscore the key role of blockade of apoptosis in preventing optimal stimulation of protective immunity. This effect was particularly evident in our studies of CD8 ${ }^{+} \mathrm{T}$ cell priming and memory $\mathrm{T}$ cell generation, in which WT M. tuberculosis showed remarkably poor immunogenicity when compared with the $\triangle \sec A 2$ mutant. $C D 8^{+} \mathrm{T}$ cells have been found by several criteria to be a significant component of antimycobacterial immunity in mouse models (33-36), and they can potentially contribute to containment or eradication of M. tuberculosis via several mechanisms. These include the secretion of protective cytokines such as IFN- $\gamma$ and TNF, cytolytic activity against infected macrophages, and even direct bactericidal effects on intracellular mycobacteria $(4,37,38)$. Although $\mathrm{CD}^{+} \mathrm{T}$ cell responses were not measurably enhanced by deletion of secA2 in our experiments (Figure 2C), we have observed that vaccination with $M$. tuberculosis strains including $\triangle \sec A 2$ generally prime stronger $\mathrm{CD}^{+} \mathrm{T}$ cell responses when compared directly with BCG (data not shown). This raises the possibility that the enhanced protection by $\triangle s e c A 2 M$. tuberculosis compared with BCG observed in the current study could be due at least in part to an augmented $\mathrm{CD}^{+} \mathrm{T}$ cell response. However, in our experience so far, the $\Delta \sec A 2$ strain is unique among $M$. tuberculosis mutants in its ability to provide a higher level of protection than BCG in animal challenge models (ref. 39 and unpublished observations). This strongly suggests that the apoptosis-promoting and $\mathrm{CD} 8^{+} \mathrm{T}$ cell-augmenting properties of $\triangle \sec A 2 \mathrm{M}$. tuberculosis are likely to be important to its ability to generate significantly increased levels of protective immunity. Further studies will be necessary to determine whether the strong protective effects of immunization with the $\Delta s e c A 2$ strain can be completely attributed to the enhanced $\mathrm{CD} 8^{+} \mathrm{T}$ cell response or whether modulation of other key components of the adaptive response is also involved.
Interestingly, it has recently been shown that $\Delta \sec A 2 \mathrm{M}$. tuberculosis exhibits attenuated growth in isolated mouse macrophages in vitro and that this phenotype is observed even in macrophages that cannot generate high levels of reactive oxygen intermediates because of inactivation of the inducible phagosome oxidase complex (40). This finding is consistent with earlier studies showing that superoxide and other reactive oxygen intermediates contribute little to the antimycobacterial activity of macrophages (41). While this does not contradict our findings on the effects of secA2 deletion on macrophage survival and $T$ cell priming, it does suggest that mycobacterial secretion of SodA is more directly protective of the host cell than of the mycobacterium itself and that the perturbation of other secreted effectors may be responsible for the attenuated growth of $\triangle \sec A 2 \mathrm{M}$. tuberculosis in macrophages.

Previous work by Kaufmann and colleagues has demonstrated that modifying BCG to express listeriolysin improves its ability to stimulate protective immunity in mice, and this may also be associated with an increased ability to induce apoptosis of macrophages (42). Our demonstration of the enhancement of long-lived adaptive immunity by the $M$. tuberculosis $\Delta s e c A 2$ mutant provides a rational and straightforward basis for improving the immunogenicity of live attenuated mycobacterial strains for use as $M$. tuberculosis vaccines (43). By combining $\triangle \sec A 2$ with additional mutations that disable various other immune evasion- and virulence-promoting functions of M. tuberculosis, it may be possible to develop a new generation of safe and effective attenuated mycobacterial vaccine strains that will have greater impact than BCG on the current global TB problem.

\section{Methods}

Bacterial strains and growth media. Virulent M. tuberculosis strains H37Rv (obtained from Trudeau Institute), Erdman, HN878 (obtained from C. Barry, Tuberculosis Research Section, NIH, Bethesda, Maryland, USA), and M. tuberculosis $\triangle$ secA2 mutant ( $\left.\mathrm{mc}^{2} 3112\right)$ have been described previously $(16,44)$. Virulent $M$. tuberculosis strains, mutants, and transformants were grown on Middlebrook 7H9 broth or 7H10 agar containing 10\% (vol/vol) oleic acid-albumin-dextrose-catalase (OADC; BD Diagnostics - Diagnostic Systems), $0.5 \%$ glycerol, and $0.05 \%$ (vol/vol) Tween- 80 . The E. coli strain $\mathrm{DH} 5 \alpha$ was used for cloning purposes and grown on Luria-Bertani agar or broth (Fisher Scientific) at $37^{\circ} \mathrm{C}$. Ampicillin $(50 \mu \mathrm{g} / \mathrm{ml})$, hygromycin $(50$ $\mu \mathrm{g} / \mathrm{ml}$ for mycobacterial selection or $150 \mu \mathrm{g} / \mathrm{ml}$ for E. coli), and kanamycin $(20 \mu \mathrm{g} / \mathrm{ml}$ for mycobacterial selection or $40 \mu \mathrm{g} / \mathrm{ml}$ for E. coli) were used to select for recombinant strains.

Construction of recombinant mycobacterial strains. For complementation of the secA2 deletion, a full-length $M$. tuberculosis secA2 gene was amplified by PCR from $M$. tuberculosis $\mathrm{H} 37 \mathrm{Rv}$ genomic DNA using primers SecC5 (5'-AAGCTTGCGTGAACGTGCACGGTTGTCCACGAATTGC-3') and SecC3 (5'-ATCGATTCAGCGGAACACCCCGGGCAGACT- 3 '). The PCR product was cloned into the pGEM vector using a TA cloning kit (Invitrogen). The fragment containing the $\sec A 2$ gene was excised and cloned into pMV361, an integrating M. tuberculosis vector with an HSP60 promoter (45). All transformations of M. tuberculosis strains were performed according to a published protocol (46).

For epitope tagging of the $19-\mathrm{kDa}$ lipoprotein, an extended primer approach was used. The 19-kDa lipoprotein gene was amplified from M. tuberculosis $\mathrm{H} 37 \mathrm{Rv}$ genomic DNA using a primer directed at the $5^{\prime}$ end of the coding sequence for the 19 -kDa lipoprotein gene $\left(5^{\prime}\right.$-GATATCGTGAAGCGTGGACTGAC-3') in combination with a $3^{\prime}$ primer extended to contain a sequence from OVA encoding amino acids 254-269 (5'-GCTAGCATTTAAAACGAGGTCCACTCGGTCAGCTTCTCGAAGTTGATGATCGACTC- 
CAGCTGCTCCAGACAGGTCACCTCGATTTCGAACGACTTG-3'). The PCR product containing the 19-kDa-OVA sequence was ligated into PMV261, a replicating extrachromosomal M. tuberculosis vector with an HSP60 promoter (45). The resulting plasmid, designated p19OVA, was used to transform WT, mutant, or complemented strains of M. tuberculosis H37Rv.

To generate a form of the SodA protein with a signal sequence recognized by the SecA1 secretion system, the sequences encoding the signal peptide of antigen $85 \mathrm{~b}$ and the entire sodA gene were amplified from M. tuberculosis $\mathrm{H} 37 \mathrm{Rv}$ genomic DNA using the primer pairs $5^{\prime}$-GATATCATGGCCACAGACGTGAGCCGAAAGATTCGAG-3' plus 5'-GCCGGGATCCCGCGCCCGCGGTTGCCGCTCCGCC-3' and 5'-GCTAGCTCAGCCGAATATCAACC-3' plus 5'-GCTAGCTCAGCCGAATATAACC-3', respectively. Each PCR product was separately cloned into the PGEM vector using a TA cloning kit (Invitrogen). In a stepwise fashion, these fragments were excised and ligated into pMV361 to create pMV3 $\alpha$-sod.

Western blot detection of OVA epitope tag expression. H37Rv, H37Rv-OVA, $\triangle \sec A 2-\mathrm{OVA}$, and $\triangle \sec A 2-\mathrm{C}-\mathrm{OVA}$ were grown to mid-log phase in $7 \mathrm{H} 9$ medium. After centrifugation, pellets were washed twice with PBS and lysed with protein extraction buffer $(50 \mathrm{mM}$ Tris- $\mathrm{HCl}, 5 \mathrm{mM}$ EDTA, $0.6 \%$ SDS, $0.06 \%$ DNase, $0.06 \%$ RNase, $0.07 \%$ pepstatin, $0.05 \%$ leupeptin, and 20 $\mathrm{mM}$ PMSF). The protein concentration of each lysate was determined by BCA assay (Pierce). Equal amounts of protein $(20 \mu \mathrm{g})$ were loaded per lane and subjected to SDS-PAGE followed by transfer to a PVDF membrane. After blocking with PBS plus 5\% skim milk, the membrane was incubated with a rabbit polyclonal anti-SIINFEKL antibody (Covance), followed by detection with a goat anti-rabbit antibody linked to HRP (Invitrogen). Specific bands were illuminated using SuperSignal West Pico stable peroxide solution (Pierce).

Apoptosis studies in BMMs and THP-1 cells. BMMs were derived according to previously published methods (5). Briefly, marrow flushed from the tibia and femurs of 6 - to 10 -week-old C57BL/6 or BALB/c mice (The Jackson Laboratory) was aseptically collected and cultured in non-tissue culture-treated $100 \times 20-\mathrm{mm}$ serological plates (Fisher) at a density of $2 \times 10^{5}$ cells $/ \mathrm{ml}$ in BMM medium (DMEM supplemented with $1 \%$ HEPES, $1 \% \mathrm{~L}$-glutamine, $1 \%$ nonessential amino acids, $100 \mathrm{U} / \mathrm{ml}$ penicillin, and $100 \mu \mathrm{g} / \mathrm{ml}$ streptomycin [all from Gibco BRL; Invitrogen], 10\% FBS [HyClone], and 10\% L929 fibroblast-conditioned medium) for 6 days. On day 6 , adherent cells were harvested after detachment by incubation for 20 minutes at $4^{\circ} \mathrm{C}$ with $5 \mathrm{mM}$ EDTA/PBS.

THP-1 cells (ATCC) were grown in RPMI-1640 (Gibco BRL; Invitrogen) supplemented with $10 \%$ FBS, $1 \%$ HEPES, $1 \%$ nonessential amino acids and essential amino acids, and $50 \mu \mathrm{g} / \mathrm{ml}$ of penicillin and streptomycin (complete RPMI). THP-1 cells were treated with $40 \mathrm{ng} / \mathrm{ml}$ PMA (Sigma-Aldrich) overnight to induce their differentiation into macrophage-like cells.

BMMs or differentiated THP- 1 cells were plated in 6-well plates at $1 \times 10^{6}$ cells per well and allowed to adhere overnight. For C57BL/6 macrophages, pretreatment with $25 \mathrm{ng} / \mathrm{ml}$ IFN- $\gamma$ (PeproTech) for 24 hours before infection was used to activate the cells and increase their sensitivity to apoptosis induction. Dispersed bacilli were incubated with cells for 3 hours (MOI of 10). The cells were then washed twice with PBS and incubated for 2-4 days as indicated in the figure legends. After infection, BALB/c BMMs were maintained in BMM medium (with 10\% L929 conditioned medium, which was necessary to prevent high background levels of spontaneous cell death), while C57BL/6 BMMs were maintained in BMM medium without L929 conditioned medium. The presence of apoptotic cells in the cell cultures was analyzed with In Situ Cell Death Detection Kit, Fluorescence (Roche Diagnostics) and Carboxyfluorescein FLICA Apoptosis Detection Kit Caspase Assay (Immunochemistry Technologies), following the manufacturer's instructions. For caspase-3 inhibition assays, THP-1 cells were treated for 1 hour before infection with the irreversible caspase- 3 inhibi- tor Z-DEVD-FMK (R\&D Systems) at a final concentration of $10 \mu \mathrm{M}$, then washed and infected with mycobacteria as indicated.

Superoxide dismutase activity assay. Equal numbers of H37Rv, $\Delta \sec A 2$, $\triangle \sec A 2-C$, and $\triangle \sec A 2-\alpha s o d A$ bacilli were first inoculated into a $10-\mathrm{ml}$ culture of Sauton liquid medium (16) and then grown at $37^{\circ} \mathrm{C}$ for 7 days. Five milliliters of the initial culture was then inoculated into $50 \mathrm{ml}$ of Sauton medium and grown for 7 days. Cultures were centrifuged, and supernatants collected and filtered through a $0.2-\mu \mathrm{m}$ filter and then concentrated 50-fold using a Centriprep centrifugal filter with a 3-kDa molecular weight limit (Millipore). Protein concentration was determined by BCA assay (Pierce). SodA activity was measured using SOD determination kitWST (Sigma-Aldrich), which uses a water-soluble tetrazolium salt, WST-1 [2-(4-iodophenyl)-3-(4-nitrophenyl)-5-(2, 4-disulfophenyl)-2H-tetrazolium, monosodium salt] that produces a water-soluble formazan dye upon reduction by superoxide produced by xanthine oxidase. Superoxide dismutase (SOD) activity is determined by the inhibition of time-dependent formation of formazan dye, which is quantitated by absorbance at $405 \mathrm{~nm}$. A volume of culture filtrate containing $3.5 \mu \mathrm{g}$ of total protein was used for duplicate determinations of SOD activity for each bacterial culture filtrate, which gave a SOD activity inhibition rate of $10 \%-14 \%$ with WT H37Rv.

ELISPOT assay for IFN $-\gamma$. ELISPOT was used to detect IFN- $\gamma$ secretion by individual $\mathrm{CD}^{+} \mathrm{T}$ cells from infected mice after stimulation with OVA peptide (SIINFEKL) in vitro. ELISPOT plates (Millipore) were coated with IFN- $\gamma$ capture antibody (BD Biosciences) for 16 hours at room temperature (RT). Plates were washed and blocked with 1\% BSA for 2 hours at RT. After treatment with rbc lysis buffer (Sigma-Aldrich), splenocytes were plated with OVA $(5 \mu \mathrm{g} / \mathrm{ml})$ peptide and cultured for 36 hours at $37^{\circ} \mathrm{C}$. After cells were removed, plates were washed with PBS followed by PBS with $0.05 \%$ Tween20 (PBST). Biotinylated anti-IFN- $\gamma$ detection antibody (BD Biosciences) was added for 2 hours at $37^{\circ} \mathrm{C}$, followed by washing with PBST. Streptavidin-alkaline phosphatase (Sigma-Aldrich) was added to the plates for 1 hour $\left(37^{\circ} \mathrm{C}\right)$, followed by washing and addition of BCIP/NBT substrate (Sigma-Aldrich). After 2 hours of incubation at $37^{\circ} \mathrm{C}$, the reaction was stopped by addition of water to the wells. Plates were fixed by addition of $4 \%$ paraformaldehyde, and spots were counted using an ELISPOT reader (Autoimmun Diagnostika). To evaluate $\mathrm{CD}^{+} \mathrm{T}$ cell responses, a similar procedure was used, except $\mathrm{T}$ cells were first separated using the Dynal Mouse T Cell Negative Isolation Kit (Invitrogen), and PPD (20 $\mu \mathrm{g} / \mathrm{ml}$; Statens Serum Institut) or peptide- 25 $(5 \mu \mathrm{g} / \mathrm{ml}$; ref. 47) of M. tuberculosis Ag85B were used as recall antigens.

In vivo cytotoxicity assay. Splenocytes were isolated from naive C57BL/6 mice, treated with $\mathrm{rbc}$ lysis buffer, resuspended at $5 \times 10^{7} / \mathrm{ml}$ in PBS with $5 \% \mathrm{FBS}$, and labeled for 5 minutes at RT with CFSE (Invitrogen) at a concentration of $0.5 \mu \mathrm{M}$ (CFSE ${ }^{\text {low }}$ cells) or $10 \mu \mathrm{M}$ (CFSE ${ }^{\text {high }}$ cells). After washing twice with PBS, the CFSElow population was pulsed with $20 \mu \mathrm{M}$ of the $\mathrm{H}-2 \mathrm{~K}^{\mathrm{b}}$-binding OVA peptide (SIINFEKL) for 1 hour at $37^{\circ} \mathrm{C}$ in complete RPMI, then washed extensively with and resuspended in PBS. The 2 CFSElabeled populations were mixed in equal proportions and injected i.v. $\left(1 \times 10^{7}\right.$ cells / mouse) into mycobacteria-infected (immune) or uninfected (naive) mice. After 16 hours, spleens were harvested, and the CFSElow and $\mathrm{CFSE}^{\text {high }}$ lymphocyte populations were quantitated using a FACSCalibur flow cytometer (BD Biosciences). Data were analyzed using WinMDI software (version 2.8; http://facs.scripps.edu/software.html), and the percent of peptide-specific lysis was calculated using the following formula: $\%$ lysis $=100-100 \times\left[\left(\right.\right.$ ratio of CFSE $^{\text {low }}$ to CFSE $^{\text {high }}$ for infected mice $) /($ ratio of CFSE ${ }^{\text {low }}$ to $\mathrm{CFSE}^{\text {high }}$ for uninfected mice)].

In vivo antigen presentation assay. Donor splenocytes were isolated from Rag1 deficient OT-1 TCR-transgenic mice (Taconic/National Institute of Allergy and Infectious Diseases [NIAID]). After rbc lysis, cells were labeled with $20 \mu \mathrm{M}$ CFSE for 5 minutes at RT at a concentration of $5 \times 10^{7}$ cells/ $\mathrm{ml}$ in PBS plus 5\% FBS. Cells were washed once with PBS plus 5\% FBS 
and twice with PBS before injection into B6.PL (Thy $1.1^{+}$) recipients (The Jackson Laboratory). Mice received either $3 \times 10^{5}$ or $1 \times 10^{7}$ labeled cells as indicated via the lateral tail vein and were then vaccinated subcutaneously or infected i.v. with $1 \times 10^{6} \mathrm{CFU}$ of $\triangle$ secA2-OVA or control bacterial strains. Splenocytes were harvested 5-7 days later, stained with anti-Thy1.2 and anti-B220 antibodies (both from BD Biosciences), and analyzed by flow cytometry. Expansion was quantified by gating on the transferred population (Thy $1.2^{+}$) and measuring the percentage of undivided (CFSEhigh) cells within this population.

Analysis of memory T cell populations. C57BL/ 6 mice were adoptively transferred with $5 \times 10^{5}$ OT- 1 cells, infected subcutaneously 24 hours later with $1 \times 10^{6} \mathrm{CFU} H 37 \mathrm{Rv}$-OVA or $\triangle$ secA2-OVA, and sacrificed at 2, 4, or 20 weeks. Splenocytes were isolated, stained with PE-labeled peptide-loaded (SIINFEKL) H-2 $\mathrm{K}^{\mathrm{b}}$ tetramers in combination with antibodies specific to Thy1.2, CD44, CD62L, and B220 (all antibodies were purchased from $\mathrm{BD}$ Biosciences). Percentages of lymphocytes staining with tetramer and expressing markers consistent with central (CD44 high $\left.\mathrm{CD} 62 \mathrm{~L}^{\text {high }}\right)$ or effector $\left(\mathrm{CD} 44^{\text {high }} \mathrm{CD} 62 \mathrm{~L}^{\text {low }}\right)$ memory cells were determined by flow cytometry. Peptide-loaded $\mathrm{H}-2 \mathrm{~K}^{\mathrm{b}}$ tetramers were obtained from the tetramer core facility at the Memorial Sloan-Kettering Cancer Center.

Vaccination and challenge studies. All animal studies were approved by the institutional animal care and use committees of the Albert Einstein College of Medicine, the Center for Biologics Evaluation and Research, and Colorado State University. C57BL/ 6 mice were vaccinated subcutaneously with $1 \times 10^{6} \mathrm{CFU}$ of M. tuberculosis $\triangle$ secA2 or M. bovis BCG-Pasteur as described previously (43). Aerogenic challenge was done 2 months later using a GlasCol inhalation chamber to deliver 50-100 CFU per animal of M. tuberculosis Beijing/W (HN878) or Erdman strains. Mice were sacrificed at 1, 3, and 5 months after challenge. Lungs and spleens of individual mice were aseptically removed and homogenized separately in $5 \mathrm{ml}$ normal saline plus $0.05 \%$ Tween- 80 using a Seward Stomacher 80 blender (Tekmar). The homogenates were diluted serially and plated on Middlebrook 7H10 agar with hygromycin $(50 \mu \mathrm{g} / \mathrm{ml})$. Lung tissues were processed for histopathology using standard paraffin fixation, sectioning, and H\&E staining. In the survival study, animals infected with M. tuberculosis Erdman were observed daily until they died or became moribund and were euthanized.

Outbred Hartley guinea pigs (Charles River Laboratories) were vaccinated intradermally with $1 \times 10^{3} \mathrm{M}$. tuberculosis $\triangle \sec A 2$ or BCG-Pasteur, followed 6 weeks later by aerosol challenge with a low dose (10-30 CFU) of virulent M. tuberculosis $\mathrm{H} 37 \mathrm{Rv}$ using a Madison chamber aerosol generation device (8). Lung, spleen, and lymph node tissues were harvested and processed for CFU determination and for histopathology at 1 and 2 months after challenge using methods similar to those described above for mice. The lymph nodes examined were a cluster located at the tracheal bifurcation that represents the tracheobronchial and cranial mediastinal nodes. For quantitative histopathological scoring of guinea pig tissue sections, sections were blindly arranged in a rank order from normal to most severe and then scored as follows: $0=$ normal, $1=$ mild, $2=$ moderate, $3=$ severe. The scoring was carried out by a veterinary pathologist and was based on the following factors: area of lung affected by inflammation; number and types of inflammatory cells; and levels of necrosis, mineralization, and fibrosis. The rank was then multiplied by the score for each section to obtain a rank score, after which the identity of the treatment groups was revealed and the mean and SD of the rank score for each group were calculated.

Statistics. One-way ANOVA was used for analyses in which 3 or more experimental groups were compared. For analyses containing 6 or fewer groups, the Bonferroni post-hoc test was used to generate $P$ values for selected pairwise comparisons. For analyses with greater than 6 groups, the Tukey post-hoc test was used. The log-rank test was used for comparison of survival curves. $P$ values of less than 0.05 were considered significant. Prism 4.0 software (GraphPad) was used for all statistical analyses.

\section{Acknowledgments}

This work was supported by NIH/NIAID grants AI063537 (PO1 to S.A. Porcelli, W.R. Jacobs Jr., and J. Chan), AI54540 (to M. Braunstein), AI054697 (to I.M. Orme) and by the TB Vaccine Testing and Research Materials Contract (NIH/NIAID HHSN266200400091c) awarded to Colorado State University. The OT-1/Rag1 mouse was obtained from the NIAID exchange program. Flow cytometry studies were facilitated by the FACS Core Resources supported by the AECOM Center for AIDS Research (AI 051519) and the AECOM Cancer Center (CA 13330). S.A. Porcelli also acknowledges support from a Burroughs Wellcome Fund Award in Translational Research and a Career Scientist Award from the Hirschl Trust. We thank John Kim, Mei Chen, Weijun Liu, Amy Yang, Crystal Shanley, and Erin Smith for expert technical assistance with animal vaccine and challenge studies and Mi-Sun Koo and Tatjana Dragic for helpful discussions and critical reading of the manuscript.

Received for publication February 26, 2007, and accepted in revised form May 21, 2007.

Address correspondence to: William R. Jacobs Jr., Howard Hughes Medical Institute and Department of Microbiology and Immunology, Albert Einstein College of Medicine, 1300 Morris Park Avenue, New York, New York, 10461, USA. Phone: (718) 430-2865; Fax: (718) 518-0366; E-mail: jacobs@aecom.yu.edu. Or to: Steven A. Porcelli, Department of Microbiology and Immunology, Albert Einstein College of Medicine, 1300 Morris Park Avenue, New York, New York, 10461, USA. Phone: (718) 430-3228; Fax: (718) 4308711; E-mail: porcelli@aecom.yu.edu.

Joseph Hinchey and Sunhee Lee contributed equally to this work.

Steven A. Porcelli and William R. Jacobs, Jr. contributed equally to this work.
1. Dye, C., Watt, C.J., Bleed, D.M., Hosseini, S.M., and Raviglione, M.C. 2005. Evolution of tuberculosis control and prospects for reducing tuberculosis incidence, prevalence, and deaths globally. JAMA. 293:2767-2775.

2. Andersen, P., and Doherty, T.M. 2005. The success and failure of BCG - implications for a novel tuberculosis vaccine. Nat. Rev. Microbiol. 3:656-662.

3. Kaufmann, S.H.E. 2005. Introduction. Rational vaccine development against tuberculosis: "Those who don't remember the past are condemned to repeat it." Microbes Infect. 7:897-898.

4. Flynn, J.L., and Chan, J. 2001. Immunology of tuberculosis. Annu. Rev. Immun. 19:93-129.
5. Houben, E.N., Nguyen, L., and Pieters, J. 2006. Interaction of pathogenic mycobacteria with the host immune system. Curr. Opin. Microbiol. 9:76-85.

6. Menaker, R.J., and Jones, N.L. 2003. Fascination with bacteria-triggered cell death: the significance of Fas-mediated apoptosis during bacterial infection in vivo. Microbes Infect. 5:1149-1158.

7. Navarre, W.W., and Zychlinsky, A. 2000. Pathogeninduced apoptosis of macrophages: a common end for different pathogenic strategies. Cell. Microbiol. 2:265-273.

8. Yrlid, U., and Wick, M.J. 2000. Salmonella-induced apoptosis of infected macrophages results in presentation of a bacteria-encoded antigen after uptake by bystander dendritic cells. J. Exp. Med. 191:613-624.

9. Keane, J., Remold, H.G., and Kornfeld, H. 2000. Virulent Mycobacterium tuberculosis strains evade apoptosis of infected alveolar macrophages. J. Immunol. 164:2016-2020.

10. Riendeau, C.J., and Kornfeld, H. 2003. THP-1 cell apoptosis in response to mycobacterial infection. Infect. Immun. 71:254-259.

11. Sly, L.M., Hingley-Wilson, S.M., Reiner, N.E., and McMaster, W.R. 2003. Survival of Mycobacterium tuberculosis in host macrophages involves resistance to apoptosis dependent upon induction of antiapoptotic Bcl-2 family member Mcl-1. J. Immunol. 
170:430-437

12. Danelishvili, L., McGarvey, J., Li, Y.J., and Bermudez, L.E. 2003. Mycobacterium tuberculosis infection causes different levels of apoptosis and necrosis in human macrophages and alveolar epithelial cells. Cell. Microbiol. 5:649-660.

13. Schaible, U.E., et al. 2003. Apoptosis facilitates antigen presentation to T lymphocytes through MHC-I and CD1 in tuberculosis. Nat. Med. 9:1039-1046.

14. Winau, F., Hegasy, G., Kaufmann, S.H.E., and Schaible, U.E. 2005. No life without death - apoptosis as prerequisite for $\mathrm{T}$ cell activation. Apoptosis. 10:707-715.

15. Winau, F., et al. 2006. Apoptotic vesicles crossprime CD8 $\mathrm{T}$ cells and protect against tuberculosis. Immunity. 24:105-117

16. Braunstein, M., Espinosa, B.J., Chan, J., Belisle, J.T., and Jacobs, R. 2003. SecA2 functions in the secretion of superoxide dismutase $A$ and in the virulence of Mycobacterium tuberculosis. Mol. Microbiol. 48:453-464.

17. De Groote, M.A., et al. 1997. Periplasmic superoxide dismutase protects Salmonella from products of phagocyte NADPH-oxidase and nitric oxide synthase. Proc. Natl. Acad. Sci. U. S. A. 94:13997-14001.

18. Kahl, R., Kampkotter, A., Watjen, W., and Chovolou, Y. 2004. Antioxidant enzymes and apoptosis. Drug Metab. Rev. 36:747-762.

19. Harth, G., and Horwitz, M.A. 1999. Export of recombinant Mycobacterium tuberculosis superoxide dismutase is dependent upon both information in the protein and mycobacterial export machinery. A model for studying export of leaderless proteins by pathogenic mycobacteria. J. Biol. Chem. 274:4281-4292.

20. Edwards, K.M., et al. 2001. Iron-cofactored superoxide dismutase inhibits host responses to $\mathrm{Myco}$ bacterium tuberculosis. Am. J. Respir. Crit. Care Med. 164:2213-2219.

21. Perskvist, N., Long, M., Stendahl, O., and Zheng, L. 2002. Mycobacterium tuberculosis promotes apoptosis in human neutrophils by activating caspase- 3 and altering expression of $\mathrm{Bax} / \mathrm{Bcl}-\mathrm{xL}$ via an oxygendependent pathway. J. Immunol. 168:6358-6365.

22. Lee, J., Remold, H.G., Ieong, M.H., and Kornfeld, H 2006. Macrophage apoptosis in response to high intracellular burden of Mycobacterium tuberculosis is mediated by a novel caspase-independent pathway. J. Immunol. 176:4267-4274.

23. Boatright, K.M., and Salvesen, G.S. 2003. Mecha- nisms of caspase activation. Curr. Opin. Cell Biol. 15:725-731.

24. Hsu, T., et al. 2003. The primary mechanism of attenuation of bacillus Calmette-Guerin is a loss of secreted lytic function required for invasion of lung interstitial tissue. Proc. Natl. Acad. Sci. U. S. A. 100:12420-12425.

25. Hogquist, K.A., Jameson, S.C., Heath, W.R., Howard, J.L., Bevan, M.J., and Carbone, F.R. 1994. T cell receptor antagonist peptides induce positive selection. Cell. 76:17-27.

26. Marzo, A.L., et al. 2005. Initial T cell frequency dictates memory CD8+ $\mathrm{T}$ cell lineage commitment. Nat. Immunol. 6:793-799.

27. Sallusto, F., Geginat, J., and Lanzavecchia, A. 2004. Central memory and effector memory $T$ cell subsets: function, generation, and maintenance. Annu. Rev. Immun. 22:745-763.

28. Barber, D.L., et al. 2006. Restoring function in exhausted CD8 T cells during chronic viral infection. Nature. 439:682-687.

29. Kaech, S.M., et al. 2003. Selective expression of the interleukin 7 receptor identifies effector CD8 T cells that give rise to long-lived memory cells. Nat. Immunol. 4:1191-1198.

30. Gillet, G., and Brun, G. 1996. Viral inhibition of apoptosis. Trends Microbiol. 4:312-317.

31. Molloy, A., Laochumroonvorapong, P., and Kaplan, G. 1994. Apoptosis, but not necrosis, of infected monocytes is coupled with killing of intracellular bacillus Calmette-Guerin. J. Exp. Med. 180:1499-1509.

32. Keane, J., Shurtleff, B., and Kornfeld, H. 2002. TNFdependent $\mathrm{BALB} / \mathrm{c}$ murine macrophage apoptosis following Mycobacterium tuberculosis infection inhibits bacillary growth in an IFN-gamma independent manner. Tuberculosis (Edinb.). 82:55-61.

33. Mogues, T., Goodrich, M.E., Ryan, L., LaCourse, R., and North, R.J. 2001. The relative importance of T cell subsets in immunity and immunopathology of airborne Mycobacterium tuberculosis infection in mice. J. Exp. Med. 193:271-280.

34. Behar, S.M., Dascher, C.C., Grusby, M.J., Wang, C.R., and Brenner, M.B. 1999. Susceptibility of mice deficient in CD1D or TAP1 to infection with Mycobacterium tuberculosis. J. Exp. Med. 189:1973-1980.

35. Derrick, S.C., Yang, A.L., and Morris, S.L. 2005. Vaccination with a Sindbis virus-based DNA vaccine expressing antigen $85 \mathrm{~B}$ induces protective immunity against Mycobacterium tuberculosis. Infect. Immun.
73:7727-7735.

36. Huygen, K., et al. 1996. Immunogenicity and protective efficacy of a tuberculosis DNA vaccine. Nat. Med. 2:893-898.

37. Cho, S., et al. 2000. Antimicrobial activity of MHC class I-restricted CD8+ T cells in human tuberculosis. Proc. Natl. Acad. Sci. U. S. A. 97:12210-12215.

38. Stenger, S., et al. 1998. An antimicrobial activity of cytolytic T cells mediated by granulysin. Science. 282:121-125.

39. Sambandamurthy, V.K., et al. 2005. Long-term protection against tuberculosis following vaccination with a severely attenuated double lysine and pantothenate auxotroph of Mycobacterium tuberculosis. Infect. Immun. 73:1196-1203.

40. Kurtz, S., McKinnon, K.P., Runge, M.S., Ting, J.P., and Braunstein, M. 2006. The SecA2 secretion factor of Mycobacterium tuberculosis promotes growth in macrophages and inhibits the host immune response. Infect. Immun. 74:6855-6864.

41. Chan, J., Xing, Y., Magliozzo, R.S., and Bloom, B.R 1992. Killing of virulent Mycobacterium tuberculosis by reactive nitrogen intermediates produced by activated murine macrophages. J. Exp. Med. 175:1111-1122.

42. Grode, L., et al. 2005. Increased vaccine efficacy against tuberculosis of recombinant Mycobacterium bovis bacille Calmette-Guerin mutants that secrete listeriolysin. J. Clin. Invest. 115:2472-2479. doi:10.1172/JCI24617.

43. Sambandamurthy, V.K., et al. 2002. A pantothenate auxotroph of Mycobacterium tuberculosis is highly attenuated and protects mice against tuberculosis. Nat. Med. 8:1171-1174.

44. Manca, C., et al. 2005. Hypervirulent M. tuberculosis W/Beijing strains upregulate type I IFNs and increase expression of negative regulators of the JakStat pathway. J. Interferon Cytokine Res. 25:694-701.

45. Stover, C.K., et al. 1991. New use of BCG for recombinant vaccines. Nature. 351:456-460.

46. Braunstein, M., Bardarov, S.S., and Jacobs, W.R., Jr. 2002. Genetic methods for deciphering virulence determinants of Mycobacterium tuberculosis. Methods Enzymol. 358:67-99.

47. Yanagisawa, S., Koike, M., Kariyone, A., Nagai, S., and Takatsu, K. 1997. Mapping of V beta $11^{+}$helper $\mathrm{T}$ cell epitopes on mycobacterial antigen in mouse primed with Mycobacterium tuberculosis. Int. Immunol. 9:227-237. 